\title{
A NATUREZA DO SABER: O LUGAR DO CONHECIMENTO NA PRÁXIS KATUKINA
}

\author{
PAULO ROBERTO HOMEM DE GÓES ${ }^{1}$
}

$U F P R$

RESUMO: O presente artigo é uma reflexão sobre a relação entre aspectos do pensamento Katukina - privilegiando suas similaridades com outros povos da família Pano -, e o ambiente florestal em diferentes planos onde esta relação é constituida. Partindo de um plano mitológico onde este se entrelaça com a práxis xamânica, busco uma aproximação de certas concepções sobre o que é considerado conhecimento e como se faz um sábio, para em seguida, versando sobre a relação dos Katukina com não-indígenas em diferentes contextos históricos, refletir sobre como estes saberes passam a constituir o principal viés de inserção e fortalecimento político dos Katukina no "mundo das mercadorias".

PALAVRAS-CHAVE: Pano; Katukina; conhecimentos tradicionais; política indígena.

ABSTRACT: The present article is a reflection upon the relationship between the aspects of Katukina knowledge- privileging its similarities with other groups of the same indigenous linguistic family called Pano- and the forest environment by different levels where this correlation is established. From a mythological perspective where it intersects with the xamanistic praxis, I look forward not only to approach certain conceptions of what is considered knowledge and how a wise man is constituted, but also to, versioning on the relation between Katukina and non-indigenous people in different historical contexts, reflect on how these knowledge starts to become the main axis of political insertion and empowerment of Katukina people in the so-called "merchandise world."

KEYWORDS: Panoan; Katukina; traditional knowledge; indigenous politic.

Mais importante que a maneira como o conhecimento é estocado em objetos externos, é o modo como as pessoas o incorporam, tanto no caso do conhecimento produtivo como da arte de viver bem e sem doença (LAGROU, 2002, p.48).

\footnotetext{
${ }^{1}$ Bacharel em Ciências Sociais e Mestrando em Antropologia Social.paulohomendegoes@hotmail.com
}

Espaço Ameríndio, Porto Alegre, v. 1, n. 1, p. 116-145, jul./dez. 2007. 
PAULO ROBERTO HOMEM DE GÓES - A natureza do saber: o lugar...

O presente artigo busca, primeiramente, uma reflexão sobre como os Katukina ${ }^{2}$, da família Pano ${ }^{3}$, concebem o que são conhecimentos sobretudo aqueles relacionados às práticas xamânicas ${ }^{4}$ - e quais são os processos para adquiri-los. Neste momento do texto enfoco a produção/aquisição dos saberes, tal como relatada em diferentes mitos e narrativas. Neste esforço analítico, dados de meu trabalho etnográfico, que está sendo realizado desde 2005, dialogam com a bibliografia Pano.

Em uma segunda parte desta reflexão, busco retraçar a história Katukina recente em sua relação com não-indígenas desde os tempos dos patrões de seringa até a demarcação das Terras Indígenas, através da memória de antigas lideranças do grupo. De forma a introduzir uma reflexão minimamente contextualizada sobre as estratégias políticas contemporâneas Katukina, enfocando no atual contexto de valorização/circulação extra-aldeias dos aspectos dos saberes indígenas e nas repercussões que este contexto promove na política interétnica.

Esta passagem, talvez demasiado brusca, de um plano cosmológico para a história e a política, se sustenta, espero eu, por dois motivos: A) Primeiro: o universo mitológico ocupa no pensamento indígena Pano um espaço sincrônico passível de ser alcançado por especialistas xamânicos, que dele extraem saberes tão práticos quanto, por exemplo, o de uma erva medicinal. Em outras palavras, entre o plano cosmológico e a ação de sujeitos históricos específicos as descontinuidades não são absolutas. B) Em segundo lugar, os produtos destas práticas estreitamente relacionadas ao universo xamânico, mitológico e ao ambiente florestal, muitas vezes denominados "conhecimentos tradicionais", é que passam contemporaneamente a

\footnotetext{
${ }^{2}$ Os Katukina são um povo de língua Pano que habita o vale do alto rio Juruá, no estado do Acre. Estão distribuídos em duas terras indígenas já demarcadas, a T. I. do rio Gregório e a T. I. do rio Campinas, ambas no município de Tarauacá -AC. A primeira é compartilhada com outro grupo Pano, os Yawanawa, e possui uma única aldeia, Sete Estrelas, que no momento não ultrapassa 50 pessoas (censo que realizei em 2006). A Terra Indígena do rio Campinas, por sua vez, concentra hoje quase a totalidade dos Katukina, segundo censo das próprias lideranças são cerca de 530 pessoas distribuídas em cinco aldeias (Campinas, Varinawa, Samaúma, Masheya e Bananeira), e é cortada em sua extensão de cerca de $18 \mathrm{~km}$, no sentido leste-oeste, pela Br-364, que é a única ligação rodoviária existente entre a capital, Rio Branco, e a segunda maior cidade do Acre, Cruzeiro do Sul.

${ }^{3}$ A família etno-linguistica Pano é composta por aproximadamente 30 mil falantes e ocupa, na região fronteiriça entre Brasil e Peru, "uma área quase ininterrupta que se estende praticamente do alto Solimões até o alto Purus (...) do Ucayali e seus afluentes da margem esquerda até as cabeceiras das bacias do Javari, do Juruá e do Purus" (ERIKSON, 1993).

${ }^{4}$ Não obstante às especificidades de cada etnia, entendo os shedipawo e o xamanismo Pano como constituídos por relações e princípios muito similares.
}

Espaço Ameríndio, Porto Alegre, v. 1, n. 1, p. 116-145, jul./dez. 2007. 
PAULO ROBERTO HOMEM DE GÓES - A natureza do saber: o lugar...

serem valorizados por camadas urbanas constituindo o viés privilegiado de inserção Katukina no "mundo das mercadorias" (GORDON, 2006).

\section{1 - Mitologia na prática: breves considerações sobre os shedipawo ${ }^{5}$ e 0 xamanismo Pano}

No começo das coisas, conforme narram os mitos Kaxinawa, a vida se desdobrava em fluxo contínuo de transformações (...) O tempo era sincronicidade, em que tudo podia ser si mesmo quanto outra coisa. Desse modo, o princípio da transformação generalizada parece ser a característica essencial da criação primordial. Com a ruptura da criação primordial, a capacidade de transformação dos primeiros seres perdeu-se, e aí se originou os planos da realidade (...) Contudo, a divisão destas realidades não é absoluta, mas tem limites fluidos, permitindo sempre a ocorrência de interferências (KEIFENHEIM, 2002, p.121 - grifo meu).

Um conceito fundamentalmente operante no pensamento possivelmente da totalidade dos povos Pano é o de yuxin ${ }^{6}$. Extremamente polissêmico, yuxin, muitas vezes é traduzido como a força vital que anima os seres vivos, como espírito, mas também é o corpo, espectro dos mortos e o poder de agência de substâncias como a água, o trovão ou o fogo (LIMA, 2000, p. 52; PÉREZ-GIL, 2006, p.3). Em contextos jocosos, entre os Katukina, yuxin simplesmente pode ser uma referência a alguém muito feio, algo como uma assombração.

Yuxin é o que possibilita a comunicação entre humanos e animais, pois é no plano da "yuxindade" (LAGROU, 1996, p.198) que a humanidade de certos animais se manifesta à visão dos pajés (romeya). Neste plano também é que a percepção dos diferentes níveis da realidade se torna possível. Enfim, embora longe de esgotar este conceito, yuxin pode ser compreendido como o próprio "princípio transformador", a que se referia Keifeinheim, e que permeia os shedipawo e também a vida ritual Pano.

\footnotetext{
${ }^{5}$ Shenipawo pode ser traduzido como "tempos dos antigos" em Yaminawa. Com o mesmo sentido ocorre alterações na pronúncia entre os Kaxinawa (Shenipabu) e Katukina (Shenepavo).

${ }^{6}$ Como no caso anterior há alterações de pronuncia entre as diferentes línguas (yuxi, yoshi, etc.), mas o sentido se preserva.
} 
PAULO ROBERTO HOMEM DE GÓES - A natureza do saber: o lugar...

O shedipawo do Relâmpago (Kana Yuxibu), que resumo a seguir, é ilustrativo de como opera este plano da "yuxindade": Uma criança nasce quando o relâmpago atinge e mata sua mãe que estava no rio. Sozinha no barranco é adotada pelos caranguejos e criada no mundo aquático. Um dia seus parentes índios a encontram brincando no rio e a levam com muita resistência para a aldeia de gente. Ela recusa a alimentar-se como índio, quer comida de caranguejo. Com o tempo se acostuma e com uns quinze anos de idade começa a querer saber de sua mãe. Contam que ela morreu quando estava grávida e está no céu. Determinado, o menino sobe ao céu, que é a mesma coisa da terra. Encontra sua mãe que casou com Kana, o relâmpago que a matou. $O$ menino resolve se vingar vira morcego e mata o relâmpago com uma arma envenenada. A mãe não gosta e ele fica com mais raiva e mata então todas suas irmãs, filhas do relâmpago, trazendo para a terra só a menor. Ela não se acostuma com a terra e seu choro força que os índios a abandonem no rio. Chegando ao fim da terra e da água ela volta ao céu permitindo a continuação da existência do relâmpago e do trovão (História do relâmpago e do trovão. ORGANIZAÇÃO DOS PROFESSORES INDÍGENAS DO ACRE, 2000).

Cada transformação de ambiente, de plano da realidade (água, terra e céu) é também uma transformação da pessoa, e é possível ao menino transitar entre os planos, retornando para os seus parentes índios. As primeiras passagens do menino (terra-água; água-terra) são forçadas, ele não escolhe ser adotado pelos caranguejos, mas se acostuma e tem o rio como sua casa; ele não quer ir embora do rio, mas é carregado e acaba forçosamente acostumando com a aldeia de gente. Em seguida é por vontade e valentia que ele transita entre terra-céu e céu-terra; sobe para buscar a mãe e se vinga de seu assassino-marido Kana Yuxibu. No entanto sua mãe já é conscientemente outra, reconhece ser ele seu filho, mas opta por continuar a viver na aldeia do céu. O menino traz então sua única irmã que deixou viva, justamente a mais nova que não escolhe vir. Ela não se acostuma e então os parentes do menino a deixam no rio onde ela é levada ao ponto onde céu, terra e água se encontram.

O nascimento trágico do menino se deve à intervenção do relâmpago que cobiça sua mãe. O relâmpago (Kana Yuxibu) é ele 
PAULO ROBERTO HOMEM DE GÓES - A natureza do saber: o lugar...

próprio um yuxin de grande poder e acaba potencializando no menino a qualidade transformadora de seu yuxin, intervenção análoga à iniciação xamânica, por isso lhe é possível transitar entre os diferentes planos da realidade.

Os yuxin não são visíveis cotidianamente para qualquer pessoa, são encantes, e, não obstante suas manifestações poderem ser observadas por qualquer pessoa em casos particulares, o plano da yuxindade é de especialidade dos pajés (romeya) e rezadores (shoitiya) ${ }^{7}$ aos quais é possível ver, em sonhos e mirações, yuxin de todos seres enquanto humanos.

Há uma concepção difundida em vários povos Pano de que cada pessoa é constituída por dois e algumas vezes três yuxin. O papel que é atribuído a cada yuxin constituinte de uma pessoa varia em cada povo, no entanto é aparentemente consensual que há um yuxin principal cujo afastamento do corpo da pessoa provoca sua morte, o transforma em outro.

Entre os Marubo diz-se que temos um yuxin do lado esquerdo do corpo, outro do lado direito e um central (Sebastião e Benedito Marubo, comunicação pessoal - abril de 2006). Quando o romeya efetua uma cura, diz-se, ele desloca um de seus yuxin auxiliares que passa a procurar o yuxin do paciente, trazendo-o de volta à pessoa adoecida. Entre os Yawanawa (PÉREZ-GIL, 2006), assim como entre os Katukina (LIMA, 2000) e Yaminawa (CALÁVIA, 2006a), distingue-se entre yuxin dos olhos (wero yuxin) e yuxin da sombra (yora vaka ou yuxin baka). Sendo que com a morte estes princípios unidos em um só corpo seguem destinos diferentes: o wero yuxin (LIMA, 2000) se desloca ao céu, enquanto o yora vaka permanece por algum tempo próximo à sepultura do falecido.

A visão e o paladar são os sentidos essenciais ou ao menos os mais valorizados do universo xamânico Pano e estão intrinsecamente relacionados. As plantas utilizadas para obtenção de visões e mesmo aquelas de uso estritamente medicinal ( $r a o$ ) são consideradas pelos diversos povos como sendo muka, ou seja, amargas. Assim como o conceito de yuxin, a distinção entre doce e amargo vem sendo longamente discutida pela bibliografia Pano desde ao menos Erikson

\footnotetext{
${ }^{7}$ Uso os termos Katukina referentes a estas especialidades.
} 
PAULO ROBERTO HOMEM DE GÓES - A natureza do saber: o lugar...

(1993), sendo retomada por Lima (2000) e Calávia (2003). Esta distinção de fato se mostra muito profícua, uma vez que muitas das plantas com características medicinais são assim designadas, seja entre os Katukina seja entre os Marubo.

O uso ritual do $u n i^{8}$, preparado inquestionavelmente muka, condensa muito bem esta relação entre as propriedades do amargo, o acesso ao plano da yuxindade e a obtenção de visões. Quando Keifeinheim (2002, p.110) pediu a descrição dos efeitos da bebida a um experiente cantador Kaxinawa do leste peruano, disse ele:

Nixi pae muda continuamente. Põe tudo em clara luz. Te deixa ver imagens mudando o tempo todo. Te deixa ver aviões. Te deixa ver barcos motorizados. Te deixa ver Kaxinawa. Te deixa ver grandes lagoas. Te deixa ver o grande crocodilo. Te deixa ver a grande cobra. Traz muitos parentes para perto. Te deixa ver um homem que quer te envenenar. Deixa ver um morto. Deixa ver a ti mesmo trabalhando. Deixa ver a ti mesmo caçando. Deixa ver grandes cidades estranhas. Deixa te ver como vais ter uma mulher. Deixa ver como vais morrer no futuro (...) (René Kaxinawa apud KEIFEINHEIM, 2002, p.110- 111).

É muito significativo, portanto, que os verbos: ver, mirar e passear são, para os Yaminawa peruanos, sinônimos, sendo designados simplesmente por oiki (EAKIN, 1991). Para os Kaxinawa (MONTAG, 1981) e Sharenawa esses verbos são distintos, mas derivam da mesma raiz, uin (uinmaikiki guiar; uinyuikiki visitar; uin ver). O estar no espaço dos sonhos e mirações de fato é concebido como estar caminhando entre lugares inacessíveis na vigília, é estar no plano da "yuxindade", que é inacessível aos olhos da experiência cotidiana, é potencialmente ver acontecimentos futuros, atividade que apenas os especialistas realizam de maneira consciente.

Os sonhos, muitas vezes induzidos pelo consumo de rome (tabaco), seja na forma de cigarro ou rapé, ao lado das mirações proporcionadas pelo uni (atividades em que um dos yuxin do curador passeia pelos vários planos da realidade e fontes indiscutíveis de conhecimentos), são experiências essencialmente visuais. A experiência

\footnotetext{
${ }^{8}$ Uni, shori, timbó, nixi pae, yagé e ayahuasca são nomes que designam a mesma bebida ritual.
} 
PAULO ROBERTO HOMEM DE GÓES - A natureza do saber: o lugar...

onírica, a experiência da miração, transcende os limites espaciais e temporais da experiência da vigília. Mani, rezador experiente entre os Katukina, certa vez me relatou que ao tomar uni na cidade do Rio de Janeiro via toda sua família que estava na aldeia.

Cipó (uni) vê tudo. Eu fui tomar cipó lá no Rio de Janeiro, aí o cipó veio e eu fiquei "bebo" de cipó, estava forte, onde eu estava via minha família todinha e quase que chorava. Daí eu cantava, cantava, aí ficou bom de cipó, daí tomei cipó de novo e apareceu a família todinha.

Mas por vezes não é o yuxin do rezador que se desloca, ou melhor, algum de seus yuxin se desloca apenas para receber ou convidar o yuxin de outros seres, freqüentemente relacionados ao espaço da floresta e das águas. O caso Marubo parece ser o que isto ocorre com maior intensidade (MONTAGNER, 1996), sendo o cumprimento da dieta necessária para que o corpo-maloca se mantenha limpo e freqüentado pelos yuxin benevolentes.

\section{Rono yuxin: o conhecimento adquirido pela aliança}

A dádiva dos animais é a única dádiva completa; mas para o comum dos mortais ela é um evento situado no tempo mítico. Ela é atualizada pelo xamã, que na contemporaneidade é capaz de superar as barreiras entre espécies para obter dos espíritos de animais e vegetais seus conhecimentos. (CALÁVIA et alli, 2003, Pp. 19)

O que parece distinguir um romeya (pajé) ou shointiya (rezador) dos demais indígenas não especialistas é justamente a capacidade de saber se mover e se guiar no espaço dos sonhos e mirações, explorando suas nuances e interagindo com os animais-espíritos que nele habitam. Nesse espaço ele aprende seus segredos, suas medicinas e canções. Canções que por sua vez é que o auxiliarão na busca de outros saberes e no exercício de seus poderes de cura e feitiço. Na realidade há a concepção de que quem canta de fato por intermédio do romeya é sua esposa-espírito-cobra, ou simplesmente rono yuxin, com a qual em 
PAULO ROBERTO HOMEM DE GÓES - A natureza do saber: o lugar...

algum momento passou a estabelecer afinidade. Conta-se que a pessoa não opta simplesmente se especializar enquanto curador, seu poder depende do rome ${ }^{9}$ (substância que os Katukina traduzem por pedra) que a rono yuxin lança no corpo do iniciante.

O encontro com a cobra é, portanto, fundamental para a aprendizagem xamânica, e, uma vez estabelecida esta aliança - que pode ocorrer de maneira contingente ou ser fruto da busca consciente , cabe ao iniciante preservar a aliança com a cobra-pajé (rono yuxin), tarefa que exige muita disciplina quanto as dietas e a ingestão freqüente de determinadas substâncias.

Lima (1998, p. 3) descreve o processo decorrente do encontro com a cobra que culmina na iniciação do rezador Katukina:

\begin{abstract}
Seja para tornar-se um romeya (xamã) ou um shoitiya (rezador/curador), um homem deve encontrar uma cobra que the revela os segredos da cura. Caçando, a caminho de casa ou mariscando, a cobra aparece no caminho de um homem, que sente estranhas sensações em seu corpo - mudança de cheiro (o corpo cheira cobra), turvamento da visão, tonturas e calafrios. Estes encontros com as cobras, são interpretados como eleição, uma indicação de que a pessoa foi escolhida para deter os conhecimentos de cura. O tamanho da cobra (muito grande/grande) parece determinar a quantidade de segredos que pode revelar e se um homem poderá atuar como xamã (romeya) ou rezador $(\text { shoitiya })^{10}$ (LIMA, 1998, p. 3).
\end{abstract}

A centralidade que as rono yuxin (exclusivamente os boídeos, sucuris ou jibóias, são assim considerados) ocupam no xamanismo Pano é notável. O Pd. Constantin Tastevin, um missionário francês que

\footnotetext{
${ }^{9}$ Note-se que a palavra Katukina para pajé, romeya, significa literalmente "tem pedra" (rome - "pedra" $+y a-$ sufixo de posse).

10 "O tema da cobra como detentora dos conhecimentos xamânicos é recorrente entre os grupos indígenas da família lingüística pano. Entre as etapas para tornar-se xamã entre os Yaminawa peruanos, Townsley (1988:133) menciona que um homem deve comer a língua e os excrementos de uma anaconda (o mais poderoso mestre dos poderes xamânicos). Os Yaminawa da fronteira brasileira dizem que para alçar a condição de xamã, um homem deve, entre outras coisas, "chupar a língua de uma ronoá (sucuri), previamente capturada e embriagada com shori (ayahuasca) (Calávia Saez 1995:107-108). Já os Kaxinawá afirmam que o preparo e as canções do ayahuasca foram aprendidos com a sucuri (Lagrou 1996). Janet Siskind (1973:165-166) observou que entre os Sharanawa um aprendiz de xamã teve seu corpo esfregado com a língua de uma cobra e comeu o coração de uma Boa constrictor" (LIMA, 1999, p.3).
}

Espaço Ameríndio, Porto Alegre, v. 1, n. 1, p. 116-145, jul./dez. 2007. 
PAULO ROBERTO HOMEM DE GÓES - A natureza do saber: o lugar...

catequizou entre vários povos indígenas da região do Alto Juruá, já em 1924 relata que entre os Katukina:

É Rono-Yonchi, o espírito serpente, que ensina aos feiticeiros a arte de curar, a arte de lançar sortilégios, a maneira de subir ao céu e de conversar com Kana, Tyuru e os espíritos dos mortos (TASTEVIN, 1924, p. 10).

Em março de 2006 quando ocorria em Curitiba a $8^{a}$ Conferência das Partes da Convenção sobre Diversidade Biológica (COP-8) alguns Katukina vieram participar das reuniões. No tempo livre e já informado de traços das concepções deles sobre as grandes cobras fiz, por dois dias, um experimento. No primeiro dia fui com o professor indígena Teka Katukina ao Passeio Público da cidade onde sabia existir um terrário com diversas espécies de cobras. A exposição começa com algumas espécies venenosas até que no fundo do ambiente encontramse salamantas e jibóias. Teka quando percebeu haver ali cobras de grande porte imediatamente saiu dizendo para que eu terminasse de olhar sozinho. Após algum tempo questionei-lhe do porque de sua atitude, ele respondeu dizendo "na minha cultura, quando a pessoa quer começar a estudar para ser pajé, ela encontra com a cobra grande. Eu não quero estudar para ser nada!" (Teka, comunicação pessoal - abril de 2006).

No dia seguinte voltamos, eu e Aro, um jovem rezador, ao terrário. Pouco antes de entrar no local ele, já avisado do que se tratava, aspirou uma boa porção de rome poto (rapé) e foi olhando com curiosidade para cada animal, ao chegar na jibóia logo disse que se tratava de uma cobra-pajé, cobra-forte. No meio do espaço, como centro da exposição, estava uma grande cobra branca de mais de quatro metros, ele olhava curioso dizendo nunca ter visto uma assim. DisseIhe, testando, que era jibóia, ele respondeu que jibóia era diferente, mas que de qualquer forma aquela era cobra muito forte, era sem dúvida cobra com espírito, em contraste com as venenosas que não possuiriam espírito e por isso podem (e devem) ser mortas. A cobra que Aro admirou pela primeira vez, mas que já sabia classificar, se tratava de uma píton, cujo habitat natural é Ásia e África. O esquema classificatório do Katukina reconheceu naquele exemplar de píton características (seus 
PAULO ROBERTO HOMEM DE GÓES - A natureza do saber: o lugar...

desenhos, tamanho, entre outras coisas) que o possibilitaram enquadrála imediatamente junto às jibóias e sucuris que são reconhecidas por seu povo como sendo muito poderosas.

Detentoras dos poderes e conhecimentos da floresta estas cobras possuem também os segredos das curas, dos cantos, das medicinas e dos feitiços. Ao iniciado cabe aprender e memorizar os ensinamentos e também seguir certas dietas positivas e negativas para conservar a rono yuxin próximo a si. Rekã e Mani, rezadores Katukina, me explicaram que quando o romeya possui muito conhecimento não é ele quem canta nos rituais de uni e sim a própria rono yuxin que o acompanha é quem canta acima de seu ombro. Ao cantar este espírito-cobra pode convidar os yuxin de outros animais para fazer parte da sessão e também cantar suas músicas, sempre através do romeya que os recebe.

O shedipawo que explica a obtenção do conhecimento do uni ${ }^{1}$ entre os Kaxinawa vincula justamente seu consumo ritual ao mundo aquático das cobras-pajés. O índio saíra para caçar e viu sair da água uma cobra que se transformou em linda mulher. A anta manteve relação com essa mulher e ele desejou fazer igual. No outro dia repetiu o que tinha visto fazer a anta, jogando três sementes na água, ao sair da água a mulher-cobra se assustou ao ver o homem. Diante de sua insistência em manter relação com ela a cobra ameaçou matá-lo, mas ele mentiu dizendo não ter família e estar disposto a casar. Ela pingou o sumo de uma planta em seus olhos e o homem foi viver na aldeia das cobras embaixo da água. Lá soube que as sucuris iam beber uni e quis participar não ouvindo o conselho de sua esposa-cobra. Bebeu e gritava que as cobras queriam matá-lo. Elas se ofenderam e ele teve de fugir. $\mathrm{O}$ bodó solidário pingou o sumo da mesma folha que o permitira acessar o mundo aquático em seus olhos para ele poder voltar para a terra. Reencontrou sua família e só depois de um ano voltou a entrar na floresta para caçar. Já no primeiro dia o homem caiu com o pé no igarapé e uma cobra pequena, seu filho, Ihe engoliu o dedo, depois veio sua filha maior e lhe engoliu o pé, até que sua esposa-cobra veio e engoliu seu corpo inteiro até os braços que manteve abertos. Seu corpo ficou todo quebrado. Seus parentes chegaram e ele mandou trazer todo

\footnotetext{
${ }^{11}$ Entre os Katukina não há, até o momento, shedipawo registrado sobre como o conhecimento do uni foi adquirido.
}

Espaço Ameríndio, Porto Alegre, v. 1, n. 1, p. 116-145, jul./dez. 2007. 
PAULO ROBERTO HOMEM DE GÓES - A natureza do saber: o lugar...

tipo de cipó até acertarem qual era o certo, fizeram o mesmo com as folhas. O homem explicou como preparar uni. Beberam durante três noites com ele cantando as músicas que tinha aprendido com as sucuris. Após isso o homem morreu e foi enterrado, de seus membros nasceram os quatro tipos de cipó conhecidos (Resumo do Shedipawo Kaxinawa extraído de Lagrou, 1996).

Sem a transição do homem da terra para a água e seu retorno para a terra, por conta do rompimento da aliança com a sucuri, os índios, seus parentes humanos, desconheceriam a ciência do preparo e as canções de sua bebida ritual. No entanto o casamento mal sucedido que lhe custara a vida não foi permanente, pois o homem do shedipawo em seu movimento pelos mundos aquático e terrestre, ao mesmo tempo inaugura a possibilidade de aliança dos índios com as cobras-pajé que não deixaram de ser, por conta de sua ação, "donas" dos segredos do uni.

Como no shedipawo a aliança do pajé com a esposa-cobra, que é o que lhe permite conhecer, é potencialmente instável. Para conservar a esposa-cobra, disse-me o já citado Mani, a pessoa deve evitar o consumo de álcool e sempre ingerir uni e rapé (rome poto), pois são substâncias amargas que a agradam fazendo-a permanecer ao lado, literalmente, da pessoa. Por não seguir esta restrição é que Kako, um jovem rezador Katukina, já fora algumas vezes criticado em público pelos rezadores mais experientes.

Como as narrativas a seguir nos indicam, no plano sinestésico do xamanismo o conteúdo das narrativas que chamamos mitológicas é, por vezes, vivenciado enquanto experiência pessoal do indígena, na realidade são estas experiências que de fato se busca através de certas dietas.

No início de junho de 2007 em Cruzeiro do Sul (AC) Yawa, um Jaminawa Arara do rio Bagé, contou para mim e Aro Katukina sobre a pesquisa que teria realizado durante oito dias na floresta. Não obstante ter sido esta narrativa contada como experiência do próprio Yawa transcrevo aqui tal como me foi possível registrar em caderno de campo. 
PAULO ROBERTO HOMEM DE GÓES - A natureza do saber: o lugar...

Sozinho munido apenas de um isqueiro, tabaco, cachimbo, nove bananas verdes e oito litros de timbó, Yawa, como é chamado em sua língua, dia após dia teria encontrado e conversado com os pajés-animais da floresta. Seus cantos primeiramente teriam acordado o macaco capelão que veio até ele para tirar satisfações; tempos depois as cantigas de Yawa atraíram a onça e por último o tamanduá-bandeira (pajé da caça). Yawa conta que se deteve apenas poucos momentos com cada um desses pajés-animais, apenas explicava que estava realizando uma pesquisa e logo continuava seu caminho. Após alguns dias perambulando pela floresta, Yawa encontrou uma índia muito linda que havia o ouvido cantar, ela se aproximou e pediu para tomar de seu vinho, ele concedeu. Beberam e cantaram juntos, ao fim da sessão a moça lhe disse que iria buscar seus parentes para ele conhecer. Tendo amanhecido o dia ela voltou com seu cunhado e sua irmã, nesta altura já o chamavam de pajé, beberam e cantaram juntos. Ao término desta sessão a moça bonita ficou com vontade de apresentar-Ihe sua mãe, combinou que era para ele esperar ali até a meia-noite. Antes do horário combinado ela apareceu com o cunhado e a irmã e disse que sua mãe viria dali algumas horas. Passado um tempo ele ouviu um som muito forte tututututututu, o vento soprou e as árvores arcaram, a coisa vai ficar boa! Pensou ele. Foi quando chegou a mãe da moça, ela se aproximou e pediu o vinho, ele deu. Depois de tomar ela avisou às filhas e ao genro que iria levar o pajé passear por duas horas pela floresta. A cada movimento que ela fazia com o rabo Ihe deixava de frente com uma medicina e dizia para que servia. Voltaram e havia três jibóias enroladas no chão, a mãe que estava como gente mandou elas levantarem, mas não queriam porque a pressão estava muito forte. Yawa pegou o cachimbo e assoprou a fumaça na cabeça de cada jibóia, no mesmo momento eram gente de novo, ficaram de pé e começaram a cantar.

A narrativa de Yawa prescindiu de explicações posteriores, apenas me disse que o encontro com as jibóias foi apenas parte de sua pesquisa e que entre outras coisas teria chegado às águas do rio Maceió, ou rio Mar, como canta em uma música que compôs em bom português ${ }^{12}$.

\footnotetext{
${ }^{12}$ Para citar um trecho: "e a jibóia vem chegando/ e a jibóia vai chegar/ ela vem toda malhada/ com os pajés que vem do mar" (Narciso Yawa Jaminawa Arara - 2007).
}

Espaço Ameríndio, Porto Alegre, v. 1, n. 1, p. 116-145, jul./dez. 2007. 
PAULO ROBERTO HOMEM DE GÓES - A natureza do saber: o lugar...

Análoga a esta narrativa em primeira pessoa registrei em dezembro de 2006 a fala do já citado Mani Katukina, considerado um shoitiya (rezador), que ao explicar o porque de Koshti (atualmente considerado como sendo o único romeya Katukina) ter mais conhecimento xamânico que ele próprio atribuiu ao fato de sua esposaespírito-cobra (rono yuxin) ser muito bonita e cantando lhe ensinar muitas coisas, que ele, Mani, não tem acesso, não obstante poder vê-la em algumas sessões de uni. Considera-se, portanto, que o romeya (pajé) tem mais conhecimento e poder do que o shointiya devido justamente à aliança que este mantém com a cobra-pajé, algo que exige dele maior observação das dietas alimentares e que impõe restrições sexuais não previstas a um rezador.

Estes relatos em primeira pessoa de Yawa e de Mani nos fornecem exemplos de como conteúdos cosmológicos são mesclados com a experiência sensível de sujeitos históricos. O pajé através do uni é quem transita no espaço-tempo dos shedipawo, sendo que neste plano da "yuxindade" (LAGROU, 1996, p. 198) os animais são vistos enquanto encantes, enquanto humanos, por isso se comunicam e estabelecem alianças com estes mediadores de mundos, ensinando-os cantos, mostrando-Ihes plantas medicinais, enfim, constituindo aquilo que estes sujeitos consideram seus próprios conhecimentos.

\section{A natureza do saber: o lugar da floresta na produção do conhecimento}

Foi cobra (rono yuxin) que ensina tudo, ensina reza, ensina virar pajé, ensina as plantas que a cobra plantou, tudo foi cobra que plantou. Eu penso assim, mas missionário diz que deus plantou (...) tudo foi cobra que fez, a onça cobra fez e deixou no mato (Mani Katukina, comunicação pessoal - dezembro 2006).

Para compreender o xamanismo Shipibo-Conibo devemos necessariamente nos referir ao ambiente. Diversos mitos identificam a fonte do poder e conhecimento - cosmológico, tecnológico, terapêutico - 
PAULO ROBERTO HOMEM DE GÓES - A natureza do saber: o lugar...

aos rao. Esse termo remete sobretudo às plantas (COLPRON, 2005, p. 108).

Da cobra-espírito surgiu a floresta (ni'i), ela própria plantou, dela vem conseqüentemente o conhecimento de todo tipo de ervas e árvores, também é dela a ciência da caça, como narra o shedipawo registrado por Lima (2000, p. 209) em que o caçador azarado ao trocar de olhos com a jibóia passa a ver por toda parte os animais que gostaria de abater. O que foi plantado por rono yuxin não é considerado planta pelos Katukina, uma vez que pertence ao ambiente não cultivado da floresta, espaço da cobra-pajé. Como em outros contextos comunitários pelo interior do país a distinção entre plantas medicinais e remédios do mato é operante, demarcando uma diferença importante na origem e conseqüentemente nas qualidades do vegetal. Entre os Katukina esta distinção permeia a relação com o uni em especial. O já referido Rekã Katukina inovou ao iniciar um cultivo de uni nas proximidades de sua casa, diz-se que isto é devido ao tempo em que deixou a aldeia e foi morar com não-indígenas em Eirunepé sul do Amazonas (aonde também aprendeu cantar músicas Kulina com um colega de trabalho). "O jeito do índio fazer é colher o cipó e as folhas da mata. Rekã aprendeu com os cariu (brancos) por isso planta", dizia Evaldo Aro criticando-o. As espécies que por excelência são consideradas do domínio selvagem da cobra-pajé, sendo coletadas no interior da mata para realização dos rituais, passaram a ser plantas através dos cuidados dele.

O romeya Katukina através do uso ritual do uni e rome e da aliança com rono yuxin pode estudar os conhecimentos que provém do espaço não cultivado da floresta (ni')).

Como vocês têm deles que é sabido, mas o estudo não se acaba. Pois é, a gente estuda e reza, aprende e reza, precisa estuda muito e fica pajé. Tudo a gente estuda, mas não é como vocês fazem não, não toma nota não, só na cabeça mesmo que a gente estuda. A gente estuda pra reza todo tempo, mas não aprendeu tudo, assim como você faz, estuda, mas não aprendeu tudo, fica velho, mas não aprendeu tudo (Mani, comunicação pessoal - dezembro 2006). 
PAULO ROBERTO HOMEM DE GÓES - A natureza do saber: o lugar...

Da floresta também extrai os elementos vegetais e animais (a divisão entre os reinos de Liceu não é estanque) de onde absorve os yuxin que vê como necessários à constituição de sua pessoa.

Os rao (remédios da mata) contribuem para a formação do corpo Shipibo-Conibo, que não cresce "naturalmente" como no modelo biológico, mas que deve ser permanentemente "construído" por uma série de procedimentos precisos (COLPRON, 2005, p. 108).

Exemplos disto são inúmeros e vão desde o costume da grávida Katukina de alisar semanalmente uma espécie de cipó, hichei txöke, em suas partes côncavas ou convexas de acordo com o desejo de parir um menino ou menina, ou mesmo o uso de altas dosagens da secreção extraída do sapo kampo para fazer do jovem um bom caçador. Tanto mais esta relação se intensifica quanto aumenta o interesse por tanai kuin (saber mais), como é o caso de todo shointiya (LIMA, 2000, p. 145).

O saber, tal como concebido pelo pensamento indígena, é antes fruto de processos contínuos voltados a aprimorar as capacidades perceptivas do pesquisador do que de uma lógica formal-discursiva. A curiosidade do estudante é assim impelida ao espaço continuo, não ordenado da floresta, ao espaço aberto. A disciplina e o rigor necessários à aquisição de conhecimentos (o caso citado de Yawa é exemplar) constituem técnicas, desenvolvidas ao longo de um tempo que nos é impossível mensurar historicamente, que incidem diretamente sobre a experiência sensível do estudante (dietas rigorosas, isolamento, etc.).

Neste sentido seria plausível dizer que os saberes, tais como concebidos pelo pensamento Pano, emergem de um cultivo intenso que é constituído por duas vias interligadas no interior do ambiente florestal: por um lado impulsiona o estudante e o especialista a vivenciar a floresta enquanto "espaço por excelência onde a ordem da realidade se transforma" (KEIFENHEIM, 2002, p. 101), extraindo dela as substâncias animais ou vegetais cujas qualidades desejáveis vêm a compor seu próprio corpo, potencializando qualidades perceptivas; por outro possibilita a atualização dos temas mitológicos, através da prática xamânica, que não pode prescindir da comunicação com os animaisespíritos, por serem eles os detentores, por excelência, do saber. 
PAULO ROBERTO HOMEM DE GÓES - A natureza do saber: o lugar...

Detenhamos-nos, agora, a outro plano desta relação entre saber e ambiente florestal, a saber, o do lugar que os conhecimentos Katukina passam a ocupar na relação com não-índios.

\section{II- Das estradas de seringa à estrada de asfalto: um breve percurso sobre a história recente dos Katukina}

Os peruanos queriam matar os índios, vinham pra levar as mulheres, o índio ia atrás de novo e tomava elas deles (...). O índio viu o branco mariscando no rio, o índio foi atrás dele e ofereceu cinco mulheres pra poder trabalhar com ele. Assim acabou as correria (Mani Katukina - abril de 2006).

A história Katukina passível de ser apreendida por nós se estende documentalmente até os registros do Pd. Constantin Tastevin no inicio do século passado. Se o pequeno sucesso de religiosos em se estabelecerem entre os povos Pano do vale do Juruá em muito se deve às teorias nativas sobre o céu e a vida pós-morte, se o paraíso cristão jamais atraiu o interesse dos $\mathrm{Nawa}^{13}$ - algo que deixara os missionários extremamente incomodados -, diferente foi com as mercadorias que os brancos dispunham em relativa abundância.

A ocupação colonizadora efetivamente ocorreu na região apenas, segundo o próprio missionário, em 1888 (TASTEVIN, 1924) através das correrias, da procura por produtos florestais (como a copaíba, o pirarucu, a carne de caça, a pele de animais silvestres, os ovos e a gordura de tartaruga, a castanha e a baunilha) e do sistema de aviamento implementado pelos seringalistas. A disputa entre caucheiros peruanos vindos do oeste e seringalistas brasileiros vindos de leste, minou a resistência indígena que perdurava na região, segundo RenardCasevitz (1992) ao menos desde o século XVI. Submetidos à violência das correrias, período que Taussig (1993), ao pesquisar a região do rio Putumayo na amazônia colombiana, viera chamar muito precisamente de "terror", muitos grupos desapareceram. Outros, ao serem

\footnotetext{
${ }^{13}$ Nawa é um termo que regionalmente os não-índios utilizam ao se referir de forma geral os grupos Pano e pode ser traduzido como "gente", da mesma forma é o termo genérico utilizado pelos indígenas para se referirem aos brancos. Aqui emprego o termo no primeiro sentido.
} 
PAULO ROBERTO HOMEM DE GÓES - A natureza do saber: o lugar...

forçosamente fixados nos seringais, foram proibidos de falar a própria língua chegando algumas vezes a serem marcados na pele, tal como se faz ao gado, com as iniciais do patrão. Somente alguns poucos povos ou frações de povos conseguiram desenvolver estratégias que oscilavam entre a aproximação e retração, de forma a possibilitar acesso às mercadorias desejadas, mas sem que isto lhes custasse a própria autonomia, como foi o caso Katukina. O já referido Pd. Constantin Tastevin, que esteve entre os Katukina em 1922, propôs uma explicação para o fato do etnônimo do grupo não ter qualquer correspondente na língua nativa.

Este grupo étnico não era, portanto, Katukina sob nenhum título: o seu nome genérico era Nouke e o seu nome específico era Wani. Por que se diziam Katukina? Supõe-se que para evitar a perseguição dos brancos. Todos os índios do grupo Pano tinham então uma reputação, talvez exagerada, de ferocidade selvagem e cruel. Centenas deles foram massacrados sem piedade pelos civilizados, e, sobretudo pelos semi-civilizados do Peru. Para escapar dessas matanças, os Wani-nawa se proclamavam Katukina, e não quiseram se reconhecer ligados aos Kachinawa, que foram as principais vítimas desses massacres (...). Aqui mesmo encontrarei representantes de outras tribos que se aliaram à mesma política: Idya e Nehe, Topa, Riniha e Wase, são Kama-nawa (onças); Koua é um Nai-nawa (uma preguiça); e entre aqueles que trabalham na borracha há Wari-nawa (sóis! ou filhos do sol), um Numa-nawa (rola) e um Sata-nawa (lontra). São sobreviventes de tribos hoje extintas, algumas massacradas pelos brancos, outras quase aniquiladas pela varíola, a doença dos brancos! (TASTEVIN, 1924, p. 5-6).

A reconfiguração de todo contexto de relações inter-étnicas da região a partir da inserção do ciclo da borracha, forçou as populações indígenas que se mantinham resistentes a este novo sistema, a intensificar práticas semi-nômades enquanto estratégias de defesa. 0 preparo e distribuição em lugares específicos de um composto alimentar que regionalmente é chamado "pão-de-índio"14 (Yawa Jaminawa Arara, comunicação pessoal - 2007), fazia parte das

\footnotetext{
14 Preparado composto pela mistura de vários tubérculos e grãos cuja característica principal é se conservar comestível por anos mesmo em ambientes pouco favoráveis (queimadas, chuvas intensas, etc.).
} 
PAULO ROBERTO HOMEM DE GÓES - A natureza do saber: o lugar...

estratégias de povos que em tempos de correria eram obrigados a permanecer em fuga constante, e nos dá exemplo de como estes grupos conseguiam se defender sem abandonar aquela que consideravam sua territorialidade. O preparo do "pão de índio" só tinha razão de ser devido ao fato de sempre se retornar a certos locais eleitos pelo grupo.

A estratégia Katukina foi intermediária se considerarmos a fixação em um seringal e a fuga constante como constituindo dois pólos de um leque de possibilidades aberto às populações nativas pelo estabelecimento violento do mercado da borracha. A narrativa do já falecido Wachime Katukina expressa como coletivamente é lembrado este primeiro período do contato com o mundo das mercadorias:

Os yara (brancos) usavam roupas e os índios queriam roupas e comida porque viviam que nem bando de porco, fugindo de um lado pro outro. O primeiro patrão estabeleceu no rio Branco (afluente do rio Gregório), mas ele começou a enganar os índios e saímos buscar outro patrão (Wachime, comunicação pessoal - 2006).

O descontentamento com os patrões aparece na memória do grupo, ao lado da feitiçaria de grupos vizinhos, como os principais motivos para novos deslocamentos, deslocamentos que ocorreram num raio de aproximadamente $70 \mathrm{~km}$ de floresta densa durante décadas. A decisão de oferecer seus conhecimentos e trabalhos (aberturas de roçado e caça de animais eram os principais serviços) aos patrões talvez tenha desacelerado um pouco o ritmo das migrações, mas longe esteve de cessá-las.

Segunda a lembrança de Wachime por volta de 1945, quando então ainda era criança, fora deslocado do seringal Sete Estrelas no rio Gregório, onde estavam seus parentes, para o seringal Kaxinawa. Sob tutela do seringalista Antonio Carioca - que certamente foi o patrão mais bem sucedido entre os Katukina - , aprendeu a falar português e fazer contas básicas de matemática. Estes conhecimentos o colocaram em posição estratégica de negociação entre seringalistas e comunidade indígena, elevando-o a posição de liderança, por ser o mediador entre os serviços prestados pelos indígenas (em especial a abertura de roçados, a caça e pesca e o conhecimento de plantas), que eram de interesse dos patrões, e a entrada das mercadorias desejadas pela 
PAULO ROBERTO HOMEM DE GÓES - A natureza do saber: o lugar...

comunidade (munição, espingardas, querosene, café, açúcar e roupas principalmente).

A saída de Carioca, cuja presença na região se estendeu por várias décadas, re-introduziu os Katukina aos movimentos constantes. Em meados da década de 1960 um certo Zacarias assumiu os seringais de Carioca, mas descontente com as negociações (esse teria roubado mais de $500 \mathrm{~kg}$ de borracha) Wachime propôs abandonar seu seringal. $O$ movimento proposto por Wachime não foi acatado por todos Katukina que acabaram se dividindo em dois grupos. Um dos grupos permaneceu nos seringais do rio Gregório e o outro liderado por ele, iniciou uma série de migrações.

Registrei em caderno de campo a reconstituição de Wachime deste tempo: Em Táuari o grupo de Wachime veio a trabalhar com Osmar por cerca de dois anos; no rio da Liberdade os Katukina trabalharam para Antonio Pontes cerca de cinco anos; para Juarez do Bom Futuro trabalharam abrindo roçados por apenas um ano; Carigó era considerado um bom patrão e por isso os Katukina permaneceram no seringal Santa Rita por seis anos; finalmente, já no início da década de 1970, vieram a trabalhar para Pereira no rio Campinas, mas nesta época os militares estavam iniciando a abertura da estrada que viera a se tornar a BR-364. Wachime ofereceu a mão-de-obra dos Katukina ao então responsável pela abertura da BR, Tenente Cunha, em troca do direito de se estabelecer na região (LIMA, 1994 e WACHIME, comunicação pessoal - 2006), a proposta foi aceita e em 1984, após conflitos com a família de seringalistas Mappes, a Terra Indígena do Campinas foi demarcada, sendo homologada em 1991 (LIMA, 1994). O fim da era dos patrões, com o estabelecimento da comunidade em uma Terra Indígena, veio a ser também senão o fim, um duro golpe na possibilidade de migrações enquanto alternativa de defesa do modo de vida Katukina, contemporaneamente lhes cabe somente optar por um território descontínuo restrito às duas Terras Indígenas que o Estado brasileiro lhes reconheceu como de direito.

As estratégias políticas seminômades adotadas pelos Katukina ao longo do século XX garantiu-lhes, ao mesmo tempo, o usufruto da relativa paz que o status de índios amansados fornecia aos nativos, e a preservação de certa autonomia com relação ao modo de vida dos 
PAULO ROBERTO HOMEM DE GÓES - A natureza do saber: o lugar...

seringais o que se expressa de forma mais evidente no fato de a totalidade de sua população ter permanecido fluente na própria língua enquanto apenas algumas pessoas vieram a aprender o português. Neste sentido é plausível dizer que as escolhas que os Katukina fizeram ao longo do período da borracha foram bem sucedidas.

Certamente nem os Katukina, nem ninguém poderia prever as implicações que a BR viria a ter sobre a vida da comunidade ou mesmo sobre a região. O evento da abertura da estrada consistiu num dos grandes marcos na história Katukina na sua relação com os brasileiros, de menor importância, talvez, apenas do que a própria chegada da empresa seringalista na região com o início das correrias.

Desde sua abertura, a BR-364 que corta a TI do rio Campinas no sentido leste-oeste em toda sua extensão de $18 \mathrm{~km}$, passou a ser o principal referencial geográfico da comunidade, pois todos indígenas vivem a menos de quinze minutos de sua margem e a utilizam como único meio de transitar entre as aldeias. Em seu limite oeste, e por conta da estrada, a TI do Campinas faz divisa com um assentamento de colonos promovido pelo INCRA, que inclui grandes extensões de pastagens e ramais que correm em sentido sul. Segundo croqui disponibilizado pela $\mathrm{OPIRJ}^{15}$, o projeto do município é estender os ramais também em sentido leste, de modo que a $\mathrm{TI}$ em pouco tempo terá suas fronteiras oeste e sul cercadas pelos ramais, assentamentos de colonização e por empreendimentos incompatíveis com a cobertura florestal.

O recente asfaltamento $^{16}$ do trecho que liga a área indígena à Cruzeiro do Sul aumentou significativamente o fluxo de veículos no interior da mesma, gerando além de um impacto ainda maior no estoque de caça da T.I., aumento em número e freqüência de Katukinas na cidade de Cruzeiro do Sul e de diferentes agentes de organizações governamentais e não-governamentais nas aldeias. A chegada dos postes de eletricidade, através do Programa "Luz para Todos" do governo federal, também é um fator de considerável impacto no cotidiano das aldeias.

\footnotetext{
${ }^{15}$ Organização dos Povos Indígenas do Alto Juruá.

${ }^{16}$ As obras foram terminadas neste trecho em 2005.
} 
Esta intensificação da relação com a chamada "sociedade envolvente" reflete nas possibilidades de estratégias que são passíveis de serem exercidas pelas lideranças Katukina contemporaneamente. Estas lideranças, a exemplo do que ocorrera com Wachime décadas antes, se constituem por aprenderem o português e assim fazerem a mediação entre os "mundos" da tradição e da mercadoria. É imprescindível considerar, no entanto, que a influência da sociedade nacional sobre a comunidade indígena tem sido cada dia mais incisiva, exigindo reformulações e impondo desafios que outrora não se colocavam.

Diferente da geração que antecedeu estas lideranças, o acesso a educação em língua portuguesa se dá não por uma relação de tutela de um seringalista, e sim pela ação de organizações indigenistas. Até o momento, as lideranças Katukina têm ocupado este espaço de mediação através de dois vieses distintos. Um representado pela inserção assalariada em instituições indigenistas como foi o caso de Fernando Kapi Katukina, que fora por alguns anos chefe de posto da Funai em Cruzeiro do Sul (AC), e de Orlando Katukina, filho de Wachime, e funcionário da Funasa. Ambos, justamente devido às funções que exercem, são os únicos Katukina que vivem fora das T.l's.

A outra possibilidade encontrada pelos Katukina tem sido estabelecer parcerias com agentes governamentais e com pessoas físicas vinculadas a terapias alternativas em grandes capitais brasileiras através de projetos formalmente institucionalizados ou não, como veremos a seguir.

\section{Estratégias políticas contemporâneas: os Katukina à caça de projetos}

Antigamente eu tomava kampô para matar caça. Hoje em dia tomo kampô para caçar projetos, para trazer recursos (Sherê Katukina, comunicação pessoal - abril de 2006).

No interior da floresta peruana há algumas décadas, rituais de caráter xamânico que tem por base o consumo de ayahuasca 
PAULO ROBERTO HOMEM DE GÓES - A natureza do saber: o lugar...

transcenderam as fronteiras dos povos indígenas e passaram a ser valorizados e praticados por diferentes grupos sociais oriundos desde regiões camponesas da própria floresta peruana, até de grandes centros urbanos de países europeus e dos Estados Unidos. Este novo boom proporcionado pela demanda moderna pelos "conhecimentos ancestrais" tem inserido esta bebida ritual indígena em uma variedade de práticas que variam desde o sincretismo religioso, passando por investigações de caráter científico até a uma espécie de mercado turístico new age do curandeirismo.

Paralelo ao contexto peruano, a absorção de práticas e pressupostos xamânicos no Brasil, também vem ocorrendo há décadas, no entanto por um viés bastante distinto. O surgimento e expansão das chamadas "religiões ayahuasqueiras" (Santo Daime, União do Vegetal e Barquinha são as de maior envergadura) por todo território nacional expressam uma forma religiosamente institucionalizada de consumo ritual da ayahuasca. O sincretismo destas religiões se expressa na absorção de aspectos da práxis xamânica (GROISMAN, 1999), especialmente o uso ritual da bebida, a conteúdos cosmológicos e rituais de orientação cristã, umbandistas e espíritas.

Certas lideranças Katukina, por sua vez, buscam contemporaneamente inserir novidades a este mosaico criado com elementos xamânicos. E o grande vetor desta inserção Katukina em diferentes camadas da população urbana no Brasil tem sido o kampo, a secreção cutânea de determinadas espécies de rãs amplamente utilizadas por vários povos de língua Pano com fins medicinais e cinegéticos. Utilizada amplamente no contexto indígena por sua eficácia contra a panema ${ }^{17}$, a secreção do kampo ganhou notoriedade a partir da década de 1990 também entre populações urbanas no Brasil (LIMA \& LABATE, 2005).

Esta difusão do uso do kampo fora das aldeias se confunde com a história de vida do ex-seringueiro Francisco Gomes Muniz. Shimbam, como era chamado entre os indígenas, que viveu entre os Katukina nas

\footnotetext{
${ }^{17}$ Panema pode ser entendida, grosso modo, como azar (na caça, nos relacionamentos, etc.) que é fruto de uma má disposição da pessoa. A fala de um velho Yawanawa pode ser ilustrativa: "a panema é como um piolho, só que é um yuxin (espírito), que fica sugando a força da gente. Daí o kampo vem e esquenta todinho o sangue e a gente passa mal, pensa que vai morrer, só que a gente agüenta, mas o yuxin (a panema) vai embora" (Raimundo Luis Yawanawa, comunicação pessoal - 2006).
} 
PAULO ROBERTO HOMEM DE GÓES - A natureza do saber: o lugar...

proximidades do rio da Liberdade durante a década de 1960. Tendo aprendido o uso medicinal e cinegético da secreção do sapo, Shimbam passou a utilizá-lo em pacientes na cidade de Cruzeiro do Sul (AC), e, posteriormente, com o reconhecimento que foi adquirindo enquanto curador, também na capital Rio Branco (LOPES, 2000 e Ni'i comunicação pessoal, 2006).

Passado algumas décadas, médicos brasileiros e estrangeiros passam a buscar Francisco Gomes para realizar aplicações de kampo, alguns por estudo, outros por tratamento, há aqueles que chegam a incorporar a "vacina do sapo" como prática terapêutica. A fama e a confiança em Francisco Gomes cresceu e através de parcerias que adquiriu nos meios médicos ele começou a realizar viagens mais longas, atingindo grandes centros como São Paulo, Brasília e Fortaleza em meados da década de 1990 (LOPES, 2000). Seu falecimento em 2001 não conteve o interesse que o kampo despertou em muita gente, e o conhecimento indígena alcançara, por suas mãos, os grandes centros urbanos.

Em 2002, Nancy, uma terapeuta ligada às religiões ayahuasqueiras, conseguiu contatar Ni'i, então presidente da recém criada Associação Katukina, com a finalidade de saber mais sobre o kampo e de levar alguns indígenas para realizarem aplicações em São Paulo. Ni'i (comunicação pessoal - 2006) conta que foi procurado pelo fato de Francisco Gomes sempre ter reconhecido que a ciência do kampo ser de origem Katukina. A parceria com Nancy foi apenas a primeira de uma série que está sendo mantida ininterrupta até os dias de hoje e que acabou gerando grande visibilidade aos Katukina em diversos setores da sociedade nacional.

Em um artigo recente sobre a expansão urbana do kampo Lima e Labate (2005) analisam estes processos considerando os significados que o uso do kampo veio a adquirir no contexto urbano e como estes novos usos vieram a proporcionar uma revalorização deste conhecimento indígena a ponto de etnias que haviam abandonado seu uso passarem a retomá-lo.

Certamente é possível afirmar que toda essa divulgação e interesse científico pelo kampo, embora promovam alguma desconfiança - afinal, as suspeitas de 
PAULO ROBERTO HOMEM DE GÓES - A natureza do saber: o lugar...

biopirataria vicejam na Amazônia - , elevou o kampo à condição de "sinal diacrítico" entre os Katukina - um marcador vistoso da identidade do grupo. Mais que uma substância capaz de livrar homens e mulheres de condições negativas, como o azar na caça ou indisposições e "fraquezas" diversas (entendidas como "preguiça"), o kampo tem facilitado aos Katukina a afirmação positiva de sua identidade (LIMA \& LABATE, 2005, p.7).

Se neste primeiro momento, diante da grande divulgação midiática e do interesse científico despertado pelo kampo, os Katukina elevaram seu uso e, sobretudo, a ciência que o envolve, à "sinal diacrítico", atualmente estas marcas de identidade têm-se estendido para outros elementos considerados tradicionais. Em junho de 2007 fui presenteado por uma liderança Katukina com duas camisetas, em uma delas vê-se a logomarca da Associação Katukina do Rio Campinas AKAC - que conta com um desenho do próprio kampo, na outra vemos o desenho de um homem voando entre estrelas e lemos rome poto Katukina, ou seja, o desenho aparece como uma clara alusão aos efeitos do rapé, eleito, ao lado do kampo, como marca da singularidade de conhecimentos indígenas.

Estas novas estratégias de inserção no mundo das mercadorias não se restringem às viagens e camisetas. Atualmente lideranças Katukina têm buscado outras formas de parcerias através da elaboração de projetos. Em parceria com terapeutas de Belo Horizonte uma liderança Katukina elaborou um roteiro turístico pelas aldeias denominado "Caminho de cura: em busca de nossa natureza interna e divina”, cujo propósito principal é divulgado em um folder eletrônico como sendo atingir o "auto-conhecimento, encontrar nosso coração, nossa direção, nosso seguimento e nossa missão(...)" (anexo I).

Paralela a esta iniciativa e apoiados pelo PDPI/ $\mathrm{MMA}^{18}$ os Katukina conseguiram aprovar o Projeto do "Hanõ Shoiti Shovo: Centro Cultural Katukina", onde pretendem segundo a fala do cacique da aldeia Campinas,

centralizar os conhecimentos das medicinas da floresta, tanto faz medicina e cura de espírito dos pajés, curandeiros. E uma parte que estamos pensando é

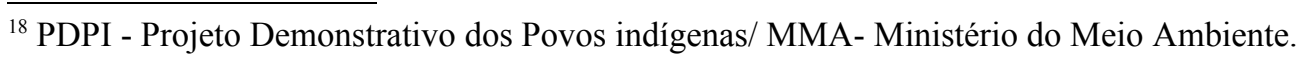


PAULO ROBERTO HOMEM DE GÓES - A natureza do saber: o lugar...

ensinar os jovens na parte de medicina, que o pessoal que conhece as medicinas são uns poucos, a gente juntando esse pessoal para o centro de cultura, faz tipo uma universidade, o interessado vai lá estuda medicina, aprende com os velhos, na prática mesmo, ali não tem teórico, vai ser tudo prática mesmo, essa planta aqui serve pra que... Daí o pessoal vai decorando (...) ali não é só pra curar, é curar aprender e ensinar, pros nosso jovem daqui, pra pessoal de fora a gente não pode ensinar, que tem diversos problemas com esse pessoal de pirataria, nosso medo é isso (...) se pessoal branco chega aqui e quiser receber atendimento dos pajeres Katukina ou medicina, eles tem que dá um jeito pra chega aqui na aldeia, daí nós encaminhamos eles para o centro cultural. (...) Pessoa que vem de fora não pode filmar, não pode fotografar, não pode perguntar sobre a medicina, - este raiz aqui serve pra que? A gente não pode explicar, porque aconteceu na história do kampo né, kampo pessoal não sabe nada, daí tinha branco chegava assim - pra que você toma kampo? Ai a gente explicava né, serve pra esse serve pra aquele, daí eles tiraram e resolveram tentar também, daí kampo deu certo serviu pra aquela doença e estão usando e já está quase no mundo inteiro, daí a gente sofrendo aqui eles tudo ganhando não sei quanto reais com a aplicação de kampo. Pra não acontecer isso a gente vai fazer esse tipo de trabalho, mas não é pra perguntar pra que serve esta raiz aqui ou aquela. Mas eles querem receber atendimento a gente atende (Tsimu, comunicação pessoal - junho de 2007 - grifo meu).

A fala de Tsimu é ilustrativa tanto no que se refere aos objetivos dos Katukina com o Centro Cultural ("centralizar os conhecimentos das medicinas da floresta") quanto a certas tensões que uma iniciativa como esta acaba gerando com relação aos novos usos que as medicinas tradicionais indígenas passam a adquirir em contato com nãoindígenas, tendo em vista a experiência que na visão dele foi negativa com a própria trajetória do kampo fora das aldeias.

Para além dos possíveis caminhos de inserção no mundo das mercadorias que contemporaneamente estão sendo traçados pelos Katukina, a relação singular que os indígenas possuem com o ambiente florestal, em especial no que se refere aos "conhecimentos tradicionais" a ele relacionados, se tornou na ultima década uma constante ao ser eleita pelos próprios Katukina como símbolo positivo de sua identidade 
PAULO ROBERTO HOMEM DE GÓES - A natureza do saber: o lugar...

étnica. Como analisado por Martins (2006), o kampo veio a se constituir como o viés através do qual os Katukina ingressaram no atual contexto projetista que permeia as relações interétnicas na Amazônia. No entanto, as últimas iniciativas Katukina (projeto do Centro cultural e roteiro turístico) têm dado mostras que o kampo é parte de um movimento mais amplo que tem feito uso da visibilidade e valorização que os "saberes da floresta" tem adquirido em diferentes camadas urbanas da sociedade nacional (cientistas, indigenistas, terapeutas, etc.), enquanto instrumento político privilegiado na "caça" aos recursos que hoje entendem como necessários à manutenção do bem estar da comunidade.

\section{Considerações finais: Saberes e mercadorias}

A concepção do que é conhecer, entre os Katukina, é indissociável do ambiente florestal. Deste ambiente provém as substâncias que formam o corpo de um sábio, potencializando a capacidade de agência de seus próprios yuxin. Neste espaço também habitam os yuxin com os quais é necessário ao especialista xamânico manter afinidade a fim de adquirir seus poderes de cura, adivinhação ou feitiço. É para o espaço aberto da floresta que o pesquisador indígena se dirige ao buscar conhecimentos seguindo as restrições necessárias segundo a orientação dos mais velhos, tendo por base, como busquei apontar, teorias complexas da percepção e de como aprimorá-las.

Com o evento do colonialismo, estes conhecimentos passaram a ser valorizados pelos patrões de seringa que exploravam uma região para eles pouco conhecida e inóspita em busca de borracha e das "drogas do sertão". Os indígenas serviram-lhes de mão de obra também na coleta do látex, mas ainda mais por conhecerem este domínio e dele saberem extrair os recursos necessários à manutenção das colocações.

Atualmente, a valorização destes saberes aos olhos de não-índios segue outros caminhos, mas a troca, por vezes nada amistosa, de saberes por mercadorias, permanece. De um lado cientistas de algumas especialidades passam a encontrar naquilo que denominam "conhecimento local" um fértil viés para o acesso a recursos genéticos 
PAULO ROBERTO HOMEM DE GÓES - A natureza do saber: o lugar...

cujos potenciais farmacêuticos são desconhecidos ou pouco estudados. De outro, a valorização de um "conhecimento ancestral" move certos terapeutas urbanos a manter alianças com alguns Katukina a fim de terem acesso in natura aos conhecimentos e substâncias de sua "cultura".

Assim como os seringalistas do passado, os "brancos urbanos" do presente (agentes estatais, cientistas ou terapeutas) ao atribuírem valor aos "conhecimentos tradicionais", abrem uma gama de possibilidades aos sujeitos indígenas que então mobilizam os aspectos mais visíveis e eficazes de seu sistema de conhecimento como forma de mediação interétnica e de efetivação de seus próprios interesses. Antes, tais saberes serviram aos Katukina como meio de adquirirem terçados, espingardas, roupas e querosene, agora servem para aquisição de bens monetários e, principalmente, expressão política no contexto acreano. A julgar pela recente aprovação junto ao Projeto Demonstrativo dos Povos Indígenas (PDPI) do primeiro projeto de iniciativa da AKAC (Associação Katukina do rio Campinas), as estratégias adotadas pelos Katukina estão sendo bem sucedidas.

A questão agora é mensurar quais serão os impactos que estas estratégias de eleição dos "conhecimentos tradicionais" como principal viés de mediação interétnica, fortalecimento político e inserção no mundo das mercadorias, terão nos processos de desenvolvimento e transmissão destes mesmos conhecimentos. Algo que, tal como ocorrera com a opção de Wachime já na década de 1970 de fixar a comunidade às margens da BR, nem os Katukina tampouco qualquer governante, terapeuta ou especialista é capaz de fazê-lo.

\section{Referências Bibliográficas}

BASSO, Ellen B. The Last Canibals: A South American Oral History. Texas: University of Texas Press Austin, 1995.

CALÁVIA SAEZ, Oscar; CARID, Miguel N.; PÉREZ-GIL, Laura. O saber é estranho e amargo: sociologia e mitologia do conhecimento entre os Yaminawa. Campos, Curitiba, n. 4, p. 9-28, 2003. 
PAULO ROBERTO HOMEM DE GÓES - A natureza do saber: o lugar...

CALÁVIA SAEZ, Oscar. O nome e o tempo dos Yaminawa: etnografia e história dos Yaminawa do rio Acre. São Paulo: Editora UNESP; ISA; Rio de Janeiro: NUTI, 2006a.

. Autobiografia e sujeito histórico indígena. Novos estudos Cebrap, São Paulo, n. 76, p. 179-195, 2006b. Disponível em: http://www.scielo.br/scielo.php?pid=S0101$33002006000300009 \&$ script $=$ sci_arttext

COLPRON, Ane-Marie. Monopólio masculino do xamanismo amazônico: o contraexemplo das mulheres xamã Shipibo-Conibo. Mana, Rio de Janeiro, v. 11 (1), p. 98125, 2005. Disponível em: http://www.scielo.br/scielo.php?script $=$ sci_arttext\&pid $=$ S0104-93132005000100004\&lng $=$ en\&nrm $=$ iso .

DESCOLA, Phillipe. Estrutura ou sentimento: a relação com o animal na amazônia. Mana, Rio de Janeiro, v. 4 (1), p. 23-45, 1998.

EAKIN, Lucille. Lecciones para el aprendizaje del idioma Yaminauha. Ministério de Educacion Instituto Lingüístico de Verano. Yarinacocha. Peru. 1991. Disponível em: http://www.sil.org/americas/peru/html/nav/pubIndex.html

ERIKSON, Philippe. Une nebuleuse compacte: le macro-ensemble pano. L'Homme, Paris, v. XXXIII (2-4), p. 45-58, 1993.

Uma singular pluralidade: a etno-história Pano. In: CARNEIRO DA CUNHA, Manuela (Org.). História dos Índios no Brasil. São Paulo: Companhia das Letras, 1992. p. 239-252.

GORDON, César. Economia selvagem: Ritual e mercadoria entre os índios Mebêngôkre. São Paulo: Editora UNESP: ISA; Rio de Janeiro: NUTI, 2006.

GROISMAN, Alberto. Eu venho da Floresta: Um estudo sobre o contexto simbólico do Santo Daime. Florianópolis: Editora da UFSC, 1999.

KEIFEINHEM, Bárbara. Nixi pae como participação no princípio de transformação da criação primordial entre os índios Kaxinawa no Leste Do Peru. In: LABATE, Beatriz C.; ARAÚJO, Wladimyr S. (Orgs.). O uso ritual da ayahuasca. Campinas: Mercado das Letras; São Paulo: Fapesp, 2002. p. 95- 126.

LAGROU, Elsje M. Xamanismo e representação entre os Kaxinawa. In: LANGDON, Jean M. (Org.). Xamanismo no Brasil: Novas perspectivas. Florianópolis: Ed. UFSC, 1996. p.197- 231.

O que nos diz a arte Kaxinawa sobre a relação entre identidade e alteridade? Mana, Rio de Janeiro, v. 8(1), p. 29-61, 2002.

LAURIOLA, Vicenzo. Ecologia global contra diversidade cultural? Conservação da natureza e povos indígenas no Brasil. O monte Roraima entre Parque Nacional e Terra Indígena Raposa-Serra-do-Sol. Ambiente \& Sociedade, Campinas, v. VI, n. I, p.83-98, jan. /jul. 2003. 
PAULO ROBERTO HOMEM DE GÓES - A natureza do saber: o lugar...

LIMA, Edilene C. Katukina: história e organização social de um povo pano do alto Juruá. Dissertação (Mestrado em Antropologia), São Paulo: USP, 1994.

Os animais no xamanismo Katukina. Comunicação apresentada no XXII Encontro Anual da ANPOCS, Caxambu: mimeo, 1998.

Com os olhos da serpente: Homens, animais e espíritos nas concepções Katukina sobre a natureza. Tese (Doutorado em Antropologia), São Paulo: USP, 2000.

LIMA, Edilene C.; LABATE, Beatriz C. De kampo a Phyllomedusa bicolor: velhos e novos usos da secreção do sapo-verde dos Katukina. Comunicação apresentada no XXIX Encontro Anual da ANPOCS, Caxambu, out. 2005.

LOPES, Leandro Altheman. Kambô, a medicina da floresta (experiência narrativa). Monografia (Graduação em Comunicação Social / habilitação Jornalismo e Editoração), São Paulo: ECA/USP, 2000.

MARTINS, Homero M. Os Katukina e o Kampô: aspectos etnográficos da construção de um projeto de acesso a conhecimentos tradicionais. Dissertação (Mestrado em Antropologia Social), Brasília: UNB, 2006.

MONTAG, Susan. Diccionario Cashinahua tomo II. Série Lingüística Peruana, n. 9, Ministério de Educacion Instituto Lingüístico de Verano. Yarinacocha. Peru, 1981. Disponível em: http://www.sil.org/americas/peru/html/nav/pubIndex.html

MONTAGNER, Delvair. Cânticos xamânicos Marubo. In: LANGDON, Jean M. (Org.). Xamanismo no Brasil: Novas perspectivas. Florianópolis: Ed. UFSC, 1996. p. 171195.

ORGANIZAÇÃO DOS PROFESSORES INDÍGENAS DO ACRE (OPIAC). Shenipabu Miyui: História dos antigos. Belo Horizonte: Ed. UFMG, 2000. 168p.

PÉREZ-GIL, Laura. O sistema médico Yawanáwa e seus especialistas: cura, poder e iniciação xamânica. Dissertação (Mestrado em Antropologia), Florianópolis: UFSC, 2006.

RENARD-CASEVITZ, France-Marie. História Kampa, memória Ashaninca. In: CARNEIRO DA CUNHA, Manuela (Org.). História dos Í́ndios no Brasil. São Paulo: Companhia das Letras, 1992. p. 197-212.

SISKIND, Janet. To hunt in the morning. London: Oxford University, 1973.

TASTEVIN, R. P. Chez les indiens du Haut-Jurua (Rio Gregório). Missions Catoliques, Paris, t. LVI, p. 65- 67; 78-80; 90-93; 101-104, 1924.

TAUSSIG, Michael. Xamanismo, Colonialismo e o homem selvagem: um estudo sobre o terror e a cura. São Paulo: Paz e Terra, 1993. 
PAULO ROBERTO HOMEM DE GÓES - A natureza do saber: o lugar...

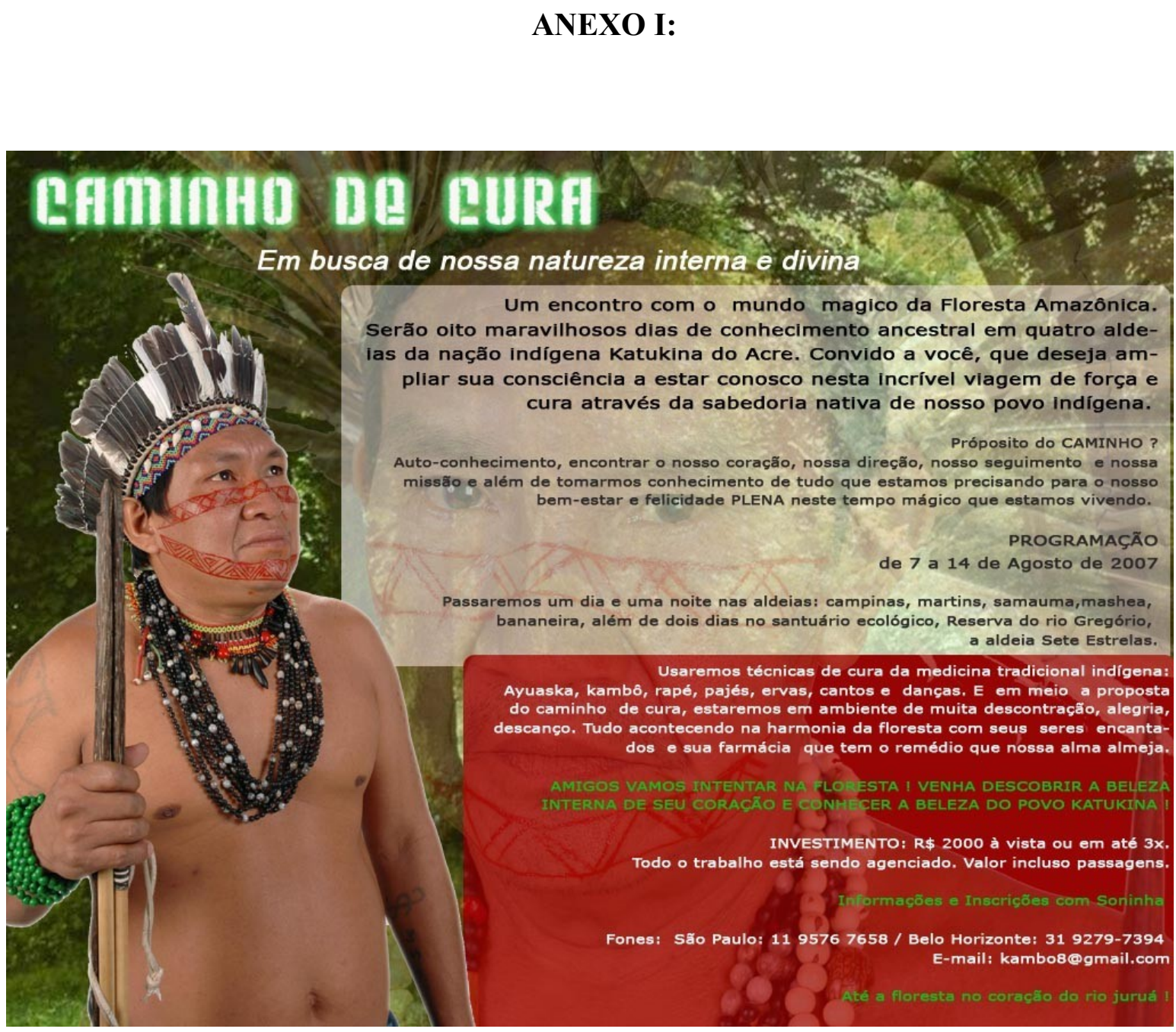

Espaço Ameríndio, Porto Alegre, v. 1, n. 1, p. 116-145, jul./dez. 2007. 